\title{
Glucose Isomerization in Simulated Moving Bed Reactor by Glucose isomerase
}

\author{
Eduardo Alberto Borges da Silva ${ }^{1}$, Antônio Augusto Ulson de Souza ${ }^{1}$, Alírio Egídio \\ Rodrigues $^{2}$ and Selene Maria Arruda Guelli Ulson de Souza ${ }^{1^{*}}$ \\ ${ }^{1}$ Laboratório de Simulação Numérica de Sistemas Químicos; Departamento de Engenharia Química e Engenharia \\ de Alimentos; Universidade Federal de Santa Catarina; eduardo@enq.ufsc.br; augusto@enq.ufsc.br; \\ selene@enq.ufsc.br; 88.040-900; Florianópolis - SC - Brasil. ${ }^{2}$ Laboratório de Processos de Separação e Reacção - \\ LSRE; Faculdade de Engenharia; Universidade do Porto; arodri@fe.up.pt; 4200-465; Porto - Portugal
}

\begin{abstract}
Studies were carried out on the production of high-fructose syrup by Simulated Moving Bed (SMB) technology. A mathematical model and numerical methodology were used to predict the behavior and performance of the simulated moving bed reactors and to verify some important aspects for application of this technology in the isomerization process. The developed algorithm used the strategy that considered equivalences between simulated moving bed reactors and true moving bed reactors. The kinetic parameters of the enzymatic reaction were obtained experimentally using discontinuous reactors by the Lineweaver-Burk technique. Mass transfer effects in the reaction conversion using the immobilized enzyme glucose isomerase were investigated. In the SMB reactive system, the operational variable flow rate of feed stream was evaluated to determine its influence on system performance. Results showed that there were some flow rate values at which greater purities could be obtained.
\end{abstract}

Key words: Simulated moving bed reactor, Glucose isomerization, enzymatic kinetics, Mass transfer, Mathematical model, Dynamic simulation

\section{INTRODUCTION}

Through reactive chromatography it is possible to integrate the processes of reaction and separation of chemical species. As a consequence of this integration, a high purity of products can be obtained and, even in reactions limited by thermodynamic equilibrium, the reactions can be directed towards the complete conversion of the reagent. Reactive chromatography can be carried out in continuous mode to promote the movement between the species fed into the fluid phase of the reactor and the solid particles, the chromatographic phase. The contact between these two phases can occur in a concurrent or countercurrent manner. The countercurrent operation can be achieved, either by the actual circulation of the particles in the chromatographic reactor, a unit therefore known as a true moving bed reactor (TMBR); or, alternatively, by an appropriate projection of the system of fluid flow, by the simulation of the circulation of the particles, an operation made possible through a simulated moving bed reactor (SMBR).

The technology of SMB together with the engineering of reactions began to appear effectively at the beginning of the 1990s. Some classes of reactions for which reactive

\footnotetext{
* Author for correspondence
} 
chromatography with the SMBR has been investigated are: reactions of esterification, alkylation, and hydrogenation, and also some enzymatic reactions (Hashimoto et al., 1983). In this study, interest turns to the process of isomerization of glucose, a reversible first order reaction of great industrial interest with a view towards the production of syrups with a high content of fructose, the so-called HFS (high/higher fructose syrups). The systems HFS are widely employed as nutritional sweeteners and also contribute to many physical and functional characteristics useful in food and drink applications.

A typical process for the production of HFS uses alpha amylase to liquefy the starch and, afterwards, a glucoamylase to saccharify the hydrolyzed starch to $95 \%$ of dextrose ready for its later isomerization. The process of isomerization results in a mixture of glucose and fructose that can be conveniently processed to produce HFS at commercial levels in fructose (i.e. 42,55 or $90 \%$ $\mathrm{w} / \mathrm{w})$. The employment of glucose isomerase (Dxylose ketol-isomerase) to catalyze the isomerization reaction of the glucose to fructose has been the largest application of the technology of immobilized enzymes over the last 40 years. The process of isomerization converts a solution of $45 \% \mathrm{w} / \mathrm{w}$ (dextrose) glucose, obtained from hydrolyzed starch, which has been previously prepared by enzymatic hydrolysis, into fructose.

Currently, the majority of isomerization processes are carried out in a plug flow reactor. In this context, two points are fundamental with respect to the immobilized enzyme for the conversion of the glucose into fructose: its activity and its stability. Some basic parameters of the process of isomerization have a crucial importance in the balance of these two characteristics: temperature, $\mathrm{pH}$ (Chen and $\mathrm{Wu}, 1987$ ), concentration of additives, impurities in the substrate, production of by-products, etc. In equilibrium, approximately 45 to $50 \%$ of glucose can be converted to fructose. On the other hand, the excessive time required for the equilibrium, as well as the presence of oligosaccharides in the substrate stream, limits the process to conversions in which HFS's are produced with 39 to $42 \% \mathrm{w} / \mathrm{w}$.

Syrup with $42 \%$ fructose is perfectly satisfactory for many purposes in the food industry. However, to obtain syrups with even higher levels of fructose, adsorption columns packed with ion exchange resins or zeolytes are frequently used.
The Simulated Moving Bed has been successfully employed in the separation of the isomers, glucose and fructose (Ching et al., 1987).

With the aim of integrating the enzymatic reaction and the process of separation in a single operation, the simulated moving bed technology was analyzed in the process of glucose isomerization. A mathematical model and a numerical methodology were developed to predict the behavior and the performance of a simulated moving bed reactive unit, and thereafter to investigate some aspects of the use of this technology in the isomerization of glucose. This work also investigated some quantitative and qualitative experimental results related to the kinetics of isomerization and mass transport when the immobilized glucose isomerase was employed.

\section{MATERIALS AND METHODS}

\section{Reaction Kinetics}

The experiments on the reaction kinetics of glucose isomerization were carried out in jacketed discontinuous reactors. The catalyst employed was the porous particle (Sweetzyme IT, from Novozymes A/S (Bagsvaerd, Denmark)). The Sweetzyme IT particle had a porous structure in which the enzyme glucose isomerase was immobilized. Sweetzyme IT consisted of browncolored cylindrical granules, with a particle size in the range of 0.4 to $1.0 \mathrm{~mm}$. The dry specific activity of the material was $400 \mathrm{IGIU} / \mathrm{g}$, with a fixed bed density of $0.33 \mathrm{~g} / \mathrm{mL}$. The sugars glucose and fructose -, and other additional chemical reagents employed were obtained from Sigma Co (Madrid, Spain). All of the chemical reagents were of analytical grade.

The Briggs-Haldane reversible mechanism for the description of the kinetics of glucose isomerization catalyzed by the enzyme glucose isomerase is given by (Convert and Borghi, 1997):

$$
\mathbf{G}+\mathbf{E} \underset{\mathrm{k}_{-1}}{\stackrel{\mathrm{k}_{1}}{\rightleftharpoons}} \mathbf{G E} \underset{\mathrm{k}_{-2}}{\stackrel{\mathrm{k}_{2}}{=}} \mathbf{F}+\mathbf{E}
$$

The $k$ parameters are the specific reaction constants for the specified reaction stages. With the hypothesis of a pseudo-stationary state for the intermediary complex (GE), and using the overall balance of the enzyme, the overall reaction rate $(r)$ for the isomerization of glucose is expressed as, 


$$
\begin{aligned}
r=E_{T} \cdot \frac{k_{1} k_{2} \cdot G-k_{-1} k_{-2} \cdot F}{\left(k_{-1}+k_{2}\right)+k_{1} G+k_{-2} F} \\
=\frac{K_{m r} V_{m f} \cdot G-K_{m f} V_{m r} \cdot F}{K_{m r} K_{m f}+K_{m r} G+K_{m f} F}
\end{aligned}
$$

where the kinetic parameters are,

$$
\begin{array}{cc}
K_{m f}=\frac{k_{-1}+k_{2}}{k_{1}} & V_{m f}=k_{2} E_{T} \\
K_{m r}=\frac{k_{-1}+k_{2}}{k_{-2}} & V_{m r}=k_{-1} E_{T}
\end{array}
$$

The total enzyme concentration is represented by $E_{T}$. The equilibrium constant $(K)$ is,

$$
K=\frac{k_{1} k_{2}}{k_{-1} k_{-2}}=\frac{K_{m r} V_{m f}}{V_{m r} K_{m f}}
$$

The acquisition of the kinetic parameters for the global reaction rate can be achieved by the Lineweaver-Burk plotting technique, where the initial reaction rates for the direct and reverse reactions are plotted with the initial concentration of the reagent species in question. The initial reaction rates are obtained by making the concentrations of glucose and fructose null in the global reaction rate.

In the experiments, reagent solutions were prepared with glucose and fructose at concentrations of $90,180,360$ and $540 \mathrm{~g} / \mathrm{L}$. The solutions contained magnesium sulfate heptahydrate $\left(\mathrm{MgSO}_{4} \cdot 7 \mathrm{H}_{2} \mathrm{O}\right)$ at a concentration of $20 \mathrm{~g} / \mathrm{L}$ with a view to maintaining the activity and stability of the enzyme (inhibiting the eventual action of calcium ions on the enzyme). Initially, all the solutions were degassed for at least two hours.
In order to maintain the $\mathrm{pH}$ of the solution constant throughout the reaction and to avoid changes in the enzyme reaction rate, $0.05 \mathrm{M}$ Tris buffer solution was employed in the preparation of the reagent solutions, so that the final $\mathrm{pH}$ of the reagent solution was between 7.7 and 7.8 (at $25^{\circ} \mathrm{C}$ ). In this case, a $\mathrm{pH}$ range of 7.7 to 7.8 was employed, due to the selection of the lower value for the temperature interval at which the enzyme presented a good activity $\left(55^{\circ} \mathrm{C}\right)$.

A volume of $60 \mathrm{~mL}$ of the reagent solution was placed in the jacketed reactors. One gram of Sweetzyme IT was added to the reactor to initiate the isomerization reaction. The immobilized enzyme was subjected to a period of re-hydration of $24 \mathrm{~h}$ in distilled water. The reactors were agitated by means of a stirrer at a rate of $150 \mathrm{~min}^{-1}$. In the course of the reaction, samples of $50 \mu \mathrm{L}$ were removed at time intervals for analysis.

Fructose and glucose were determined by HPLC analysis using a refraction index detector (Gilson, model 131) and an ionic column - Transgenomic ${ }^{\mathrm{TM}}$ ICSep ION-300 (Transgenomic Inc., USA).

The kinetic parameters for Eq.(1) were obtained from the angular and linear coefficients of the Lineweaver-Burk graphs from the curves of the experimental data (Table 1). Figure 1 presents the initial reaction rate with the initial concentrations of the sugars - forward and reverse reaction.

From Table 1, the comparison between the values of the kinetic parameters for the isomerization of glucose in this study with other values from the literature showed that in spite of the operational conditions being slightly different, as well as the activities of the enzymes used, the parameters compared favorably, thereby confirming the validity of the procedure adopted for estimation of the kinetics of isomerization.

Table 1 - Comparison of the values for the kinetic parameters of glucose isomerization in this study with values from studies published previously.

\begin{tabular}{lccc}
\hline Kinetic parameters & Chen and Wu $\mathbf{~}^{\mathbf{1}} \mathbf{( 1 9 8 7 )}$ & Convert and Borghi $^{\mathbf{2}} \mathbf{( 1 9 9 7 )}$ & This work $^{\mathbf{3}}$ \\
\hline$V_{m f}\left(\mu \mathrm{mol} / \mathrm{min}_{\mathrm{Enz}}\right)$ & $2.92 \times 10^{2}$ & $3.95 \times 10^{2}$ & $3.16 \times 10^{2}$ \\
$V_{m r}\left(\mu \mathrm{mol} / \mathrm{min} \mathrm{g}_{\mathrm{Enz}}\right)$ & $1.87 \times 10^{2}$ & $2.59 \times 10^{2}$ & $2.60 \times 10^{2}$ \\
$K_{m f}(\mathrm{~mol} / \mathrm{L})$ & 0.70 & 0.70 & 0.54 \\
$K_{m r}(\mathrm{~mol} / \mathrm{L})$ & 0.45 & 0.45 & 0.46 \\
$K$ & 0.99 & 0.98 & 1.04 \\
\hline
\end{tabular}

${ }^{1}$ Chen and $\mathrm{Wu}$ (1987) - enzyme Sweetase (250IGUI/g); $\mathrm{T}=60^{\circ} \mathrm{C} ; \mathrm{pH}=8.25$;

${ }^{2}$ Convert and Borghi (1997) - enzyme Sweetzyme $T$ (350IGUI/g); $\mathrm{T}=60^{\circ} \mathrm{C} ; \mathrm{pH}=8.25$;

${ }^{3}$ This study - enzyme Sweetzyme IT (400IGUI/g); T = 55० $\mathrm{C}$; $\mathrm{pH}=7.7-7.8$. 

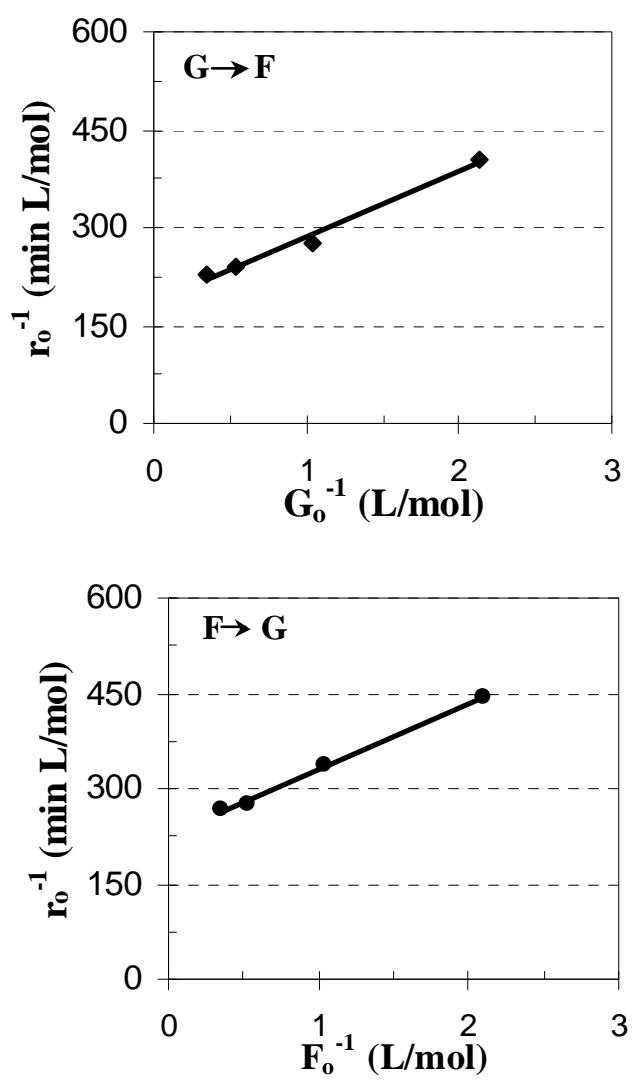

Figure 1 - Lineweaver-Burk plots of (a) forward and (b) reverse reactions by glucose isomerase Sweetzyme $I T-$ at $55^{\circ} \mathrm{C}$.

\section{Mass Transfer Effects}

Since the glucose isomerization took place in the presence of porous particles where the enzyme was immobilized, the internal - diffusion through the pores - and external mass transfer-diffusion in the film - of the reagent must be determined.

In this study, the influence of resistance to external and internal mass transfer of the sugars in the conversion of the process of glucose isomerization has been obtained.

\section{Resistance to external mass transfer}

In order to determine the effects of the external mass transfer a packed bed reactor - a Superformance 26 column (Gotec Labortechnik, Muhltal) - was used. The height of the fill was altered to maintain the residence time for the reagent feed solution constant. If the effects of the external diffusion were significant, the change in the linear velocity would result in a change in the conversion of the reactor.
The reactor was packed with different quantities of the commercial enzyme Sweetzyme IT (5.25, 8.76 and $15.78 \mathrm{~g}$ ). The feed solution contained glucose at a concentration of $180 \mathrm{~g} / \mathrm{L}(1 \mathrm{M})$, buffered with $0.05 \mathrm{M}$ Tris solution at a $\mathrm{pH}$ of 7.7 , and with magnesium sulfate heptahydrate at $20 \mathrm{~g} / \mathrm{L}$. The temperature in the jacket of the reactor, as well as that of the feed solution, was $55^{\circ} \mathrm{C}$. Table 2 presents the results of conversion obtained for the different catalytic fill heights.

Despite the low flows employed, the external transport did not appear to be the limiting factor for glucose isomerization on the particles of Sweetzyme IT. It was confirmed, therefore, that the limitation to the external mass transport of the reagent to the catalyst particle was negligible, returning practically constant conversion values for different catalytic fill heights with the same residence time. 


\section{Resistance to internal mass transfer}

This study involved the qualitative determination of the influence of the internal resistance to mass transfer in the particles of Sweetzyme IT employing different particle sizes for the catalyst in the reactor packing and determining the conversion of the glucose isomerization reaction.

The Sweetzyme IT particles were supplied commercially in a range of particle diameters from 0.4 to $1 \mathrm{~mm}$ (according to Novozymes $A / S$ ). Sieves were employed in order to obtain specific particle sizes (ASTM E-11-79, U.S. series) that provided size ranges for the immobilized enzyme of: 500 to $600 \mu \mathrm{m} ; 600$ to $710 \mu \mathrm{m} ; 710$ to $850 \mu \mathrm{m}$; and greater than $850 \mu \mathrm{m}$ (very low fraction in the sample).
The same fixed bed reactor employed to investigate the influence of the resistance to external mass transfer in the catalytic reaction of glucose isomerization also was employed in this analysis: a Superformance 26 jacketed column. The reactor was packed with equal quantities of the enzyme Sweetzyme IT $(6.6 \mathrm{~g})$ for three different ranges of particle size: 500 to $600 \mu \mathrm{m}$, 710 to $850 \mu \mathrm{m}$ and greater than $850 \mu \mathrm{m}$. The packing densities for the three cases was an average value of approximately $0.33 \mathrm{~g} / \mathrm{mL}$. The enzyme samples were re-hydrated for a minimum of 60 minutes in a beaker containing the same substrate as that to be used in the feed of the reactor.

Table 2 - Study of the influence of the resistance to external mass transfer in the conversion of glucose to fructose employing Sweetzyme IT particles.

\begin{tabular}{cccc}
\hline Height $(\mathbf{c m})$ & Mass, $\boldsymbol{W}(\mathbf{g})$ & $\begin{array}{c}\text { Flow rate, } \boldsymbol{Q} \\
(\mathbf{m L} / \mathbf{m i n})\end{array}$ & Conversion, $\mathbf{X}(\boldsymbol{\%})$ \\
\hline 2.8 & 5.25 & 2.97 & 0.304 \\
4.6 & 8.76 & 4.96 & 0.298 \\
8.3 & 15.78 & 8.93 & 0.306 \\
\hline
\end{tabular}

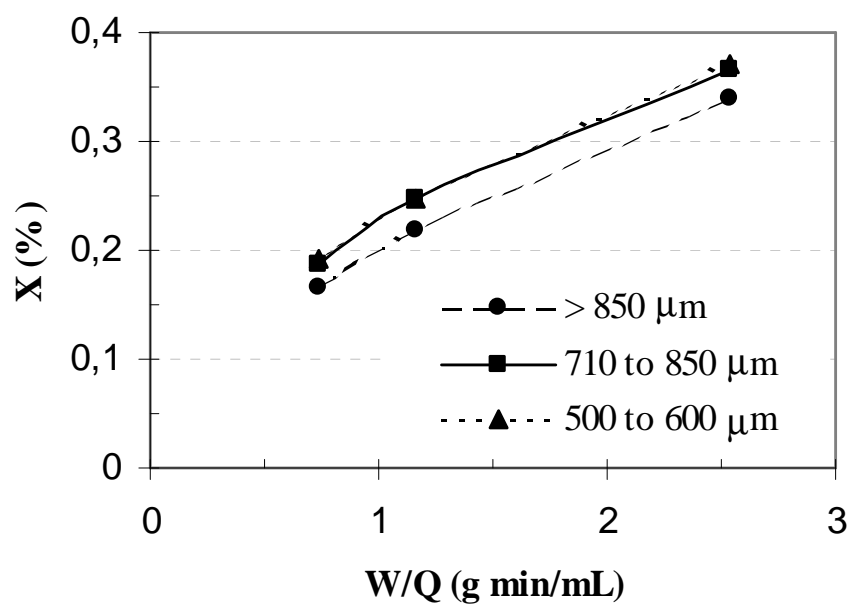

Figure 2 - Conversion of glucose in the fixed bed reactor packed with different sizes of Sweetzyme IT particles with different residence times. Effect of the resistance to internal mass transfer.

The reagent substrate was a solution of glucose at a concentration of $120 \mathrm{~g} / \mathrm{L}$ containing $0.05 \mathrm{M}$ Tris solution - $\mathrm{pH}$ of 7.9 (at $25^{\circ} \mathrm{C}$ ) - and magnesium sulfate heptahydrate at $20 \mathrm{~g} / \mathrm{L}$. The volumetric flows of feed applied employing the HPLC pump were 2.6, 5.7 and $8.9 \mathrm{~mL} / \mathrm{min}$. The operating temperature - in the reactor jacket and in the feed solution - was $55^{\circ} \mathrm{C}$.

The results of this experiment are presented in Fig. 2. In general, when there was limitation by 
diffusion, the conversion increased as the diameter of the catalyst particles decreased. A tendency was identified towards an increase in the conversion with the decrease in the size of the particles of Sweetzyme IT; however, the most marked difference was observed only when the particles were greater than $850 \mu \mathrm{m}$. For particles in the size ranges between 500 and $600 \mu \mathrm{m}$ and 710 and 850 $\mu \mathrm{m}$, the conversion values were very similar.

The observation in Figure 2 lead to the conclusion that for particles of Sweetzyme IT below $0.85 \mathrm{~mm}$, the internal diffusion resistance was very low and could be ignored. Effective factors close to the unit have been reported in a number of species of immobilized glucose isomerase (Linko et al., 1981). Palazzi and Convertti (2001) also investigated the diffusional resistance in the process of glucose isomerization employing the immobilized glucose isomerase. They found that the internal resistance was significant only for particles with a radius greater than $1 \mathrm{~mm}$.

\section{MATHEMATICAL MODEL}

In the process of glucose isomerization, the main interest lies in converting the maximum possible amount of glucose to fructose. With the isomerization being a reversible reaction, the equilibrium limits the conversion with a reaction constant dependent on the unit. In this study of the isomerization of glucose linked to the SMB technology, the system proposed by Hashimoto et al. (1983) was considered. The SMB hybrid unit is associated with fixed bed reactors, and provides a saving of eluent in comparison with the system composed of an enzymatic reactor preceding a SMB separator unit. The enzymatic reactors present in the system appear only in section 3 (reaction section), that is, soon after the feed stream, as can be seen in Fig. 3. The reactors followed the permutation of the external streams in the switching time intervals, $t^{*}$. The unit was composed of three sections in which a maximum conversion of glucose was convenient in section 3 in switch order to prevent contamination of the extract stream (fructose).

The analysis of the system configuration was carried out by mathematical modeling and the dynamic simulation of the reactive unit.

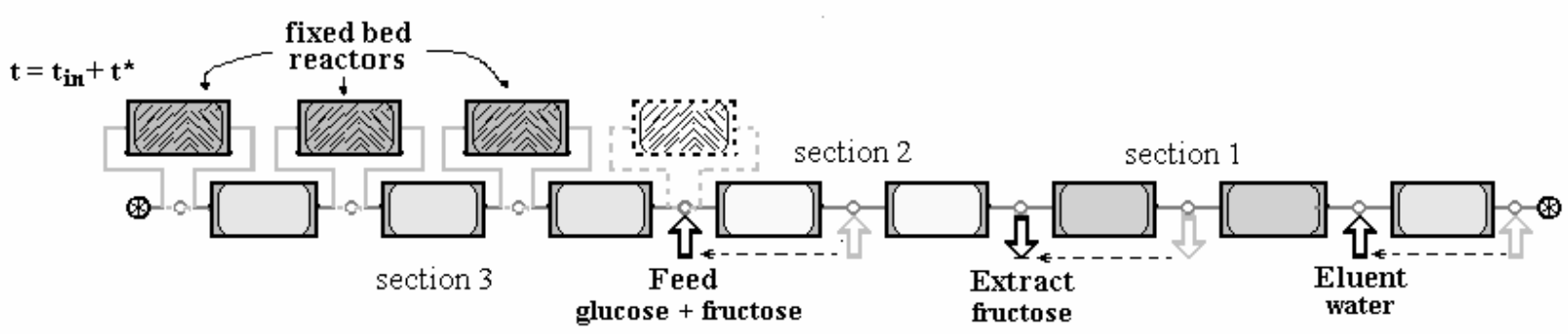

Figure 3 - System: simulated moving bed unit together with fixed bed reactors for the isomerization of glucose.

The model was based on the equivalence between the SMBR and the TMBR, considering the relationships of equivalence of the units. The mass balance in the two phases - liquid and solid -of the unit, in a model of equivalence, gave the following set of governing equations:

- Mass balance in the fluid phase for the species $i(i=$ fructose, glucose);

- Adsorption columns $k$,

$$
\begin{array}{r}
\frac{\partial\left(C_{i k}\right)}{\partial t}+\frac{(1-\varepsilon)}{\varepsilon}\left[\frac{\partial\left(\bar{q}_{i k}\right)}{\partial t}-u_{s} \frac{\partial\left(\bar{q}_{i k}\right)}{\partial z}\right]+ \\
+v_{k} \frac{\partial\left(C_{i k}\right)}{\partial z}-D_{a} \frac{\partial^{2}\left(C_{i k}\right)}{\partial z^{2}}=0
\end{array}
$$

present in sections 1, 2 and 3. In Eq. (5) $v_{k}$ is the interstitial velocity of the fluid phase in column $k$, and $u_{s}$ is the velocity of the solid phase, $D_{a}$ is the axial dispersion coefficient, and $\varepsilon$ is the porosity. The concentrations of species in the fluid phase 
and in the adsorbent phase are represented by $C_{i k}$ and $\bar{q}_{i k}$, respectively.

- Reaction $k$ columns,

$\frac{\partial\left(C_{i k}\right)}{\partial t}+v_{k} \frac{\partial\left(C_{i k}\right)}{\partial z}-D_{a} \frac{\partial^{2}\left(C_{i k}\right)}{\partial z^{2}}+\frac{\left(1-\varepsilon_{r}\right)}{\varepsilon_{r}} \cdot r_{i}=0$

present in section 3 , only. The reaction rate of the process is represented by $r_{i}$ and $\varepsilon_{\mathrm{r}}$ is the porosity of the reactors.

- Mass balance for adsorbent solid phase (Linear Driving Force approximation):

$\frac{\partial\left(\bar{q}_{i k}\right)}{\partial t}=u_{s} \frac{\partial\left(\bar{q}_{i k}\right)}{\partial z}+k_{T M}\left(q_{i}^{*}-\bar{q}_{i k}\right)$

referring to the adsorption columns. The term $q_{i}{ }^{*}$ indicates the equilibrium concentration for the species in the solid phase with the fluid phase and $k_{T M}$ the global coefficient of mass transfer.

The balance equations for the fluid phase have the Danckwerts boundary conditions and for solid phase, saturation condition and continuous mass flux of species are used.

Initial conditions $(t=0)$ :

$C_{i k}=\bar{q}_{i k}=0$

Boundary conditions for the reaction and adsorption columns:

$z=O(t>0):$

$v_{z k} C_{i k, o}=\left.v_{z k} C_{i k}\right|_{z=0^{+}}-\left.D_{a} \frac{\partial\left(C_{i k}\right)}{\partial z}\right|_{z=0^{+}}$

$\left.\frac{\partial\left(q_{i k}\right)}{\partial z}\right|_{z=0}=0 \quad$ (except for reactors)

$z=L_{C}(t>0)$

$\left.\frac{\partial\left(C_{i k}\right)}{\partial z}\right|_{z=L_{C}}=0$

$\bar{q}_{i k}=\bar{q}_{i k+1, o} \quad$ (only for adsorption columns in sections 1 and 2) $\bar{q}_{i k}=\bar{q}_{i k+2, o} \quad$ (only for adsorption columns in section 3 , with $k+2=1$ when greater than the maximum number of subsections)

Each column plays different functions during the process, depending on its location (section). Therefore, the boundary conditions depend on the section of the system and the mass balances in the nodes of the moving bed unit identify the sections considered:

- for columns within one section and for the extract node:

$C_{i k+1, o}=C_{i k}$

- for the eluent node:

$C_{i k+1, o}=\frac{v_{3}}{v_{1}} C_{i k}$

- for the feed node:

$C_{i k+1, o}=\frac{v_{F e}}{v_{3}} C_{i F e}+\frac{v_{2}}{v_{3}} C_{i k}$

The variables $v_{1}, v_{2}$ and $v_{3}$ are the velocities of the fluid phase in sections 1,2 and 3 of the bed. The variables $C_{F e}$ and $v_{F e}$ are the concentration of the species and the velocity of the feed stream. The overall balances in nodes that precede the sections of the unit complete the mathematical modeling. The development of these model equations can be found elsewhere (Silva et al., 2002).

\section{RESULTS AND DISCUSSION}

For the process of glucose isomerization to operate adequately in the configuration shown in Fig. 3, thereby enabling the reaction and the separation in the intended sections, the appropriate selection of fluid flows in each section and of switching time is fundamental. The restrictions that must be satisfied for the recovery of fructose in extract stream and to promote the reaction in section 3 are expressed in terms of liquid flows of the species in each section. Mathematically, considering that the adsorption equilibrium of the sugars can be represented by linear isotherms, the following is defined: 


$$
\gamma_{i j}^{*}=\frac{v_{j}}{u_{S}} \frac{\varepsilon}{1-\varepsilon} \frac{1}{K_{i j}}
$$

where $j$ refers to the sections. Then, the restrictions for the system are shown as,

$$
\begin{aligned}
& \gamma_{F r 1}^{*}>1 ; \gamma_{G l 1}^{*}>1 \\
& \gamma_{F r 2}^{*}<1 ; \gamma_{G l 2}^{*}>1 \\
& \gamma_{F r 3}^{*}<1 ; \gamma_{G l 3}^{*}>1
\end{aligned}
$$

These flow restrictions were employed by Hashimoto et al. (1983) when the authors published simulation studies following this concept of operation for the process of isomerization using the system illustrated. Later, Ching and $\mathrm{Lu}$ (1997) indicated that these restrictions do not need to be strictly satisfied since it is not only the separation that is in force but also the reaction. Furthermore, with the new criterion of performance to be included conversion - some restrictions can be broken. Table 3 presents the parameters employed in the experimental and simulation studies of Hashimoto et al. (1983) and Ching and Lu (1997).

In the case of Table 3 , the reaction is described by the kinetics (Ching and Lu, 1997):

$$
r_{i}=k_{r}\left(C_{G l}-C_{F r}\right)
$$

With the values from Table 3 , we could see the values for the flow parameters defined by Hashimoto et al. (1983) - Table 4 - and the values indicated by Ching and $\mathrm{Lu}$ (1997), when the restriction in section 2 was violated.

Table 3 - Operating conditions and parameters for the model of glucose isomerization in a SMBR (Ching and Lu, 1997; Hashimoto et al., 1983).

\begin{tabular}{cccc}
\hline \multicolumn{2}{c}{ Operating Conditions } & \multicolumn{2}{c}{ Parameters } \\
\hline$C_{G l, o}$ & $1.0 \mathrm{M}$ & $k_{T M}^{F r} ; k_{T M}^{G l}$ & $0.41 \mathrm{~min}^{-1}$ \\
$C_{F r, o}$ & $1.0 \mathrm{M}$ & $K_{F r}$ & 0.686 \\
$Q_{F e}$ & $K_{G l}$ & 0.586 \\
$Q_{E l}$ & $0.14 \mathrm{~mL} / \mathrm{min}$ & $k_{r}$ & $0.0617 \mathrm{~min}^{-1}$ \\
$Q_{3}$ & $0.43 \mathrm{~mL} / \mathrm{min}$ & Num. Columns & 21 \\
$t^{*}$ & $4.00 \mathrm{~mL} / \mathrm{min}$ & $\left.L_{C}-\underline{\mathrm{R}}-3-3\right)$ \\
$\varepsilon ; \varepsilon_{r}$ & $3.0 \mathrm{~min}$ & $D i$ & $10.2 \mathrm{~cm}$ \\
\hline
\end{tabular}

The average concentration profile of the species over the course of the SMBR in the process of glucose isomerization, is presented in Fig. 4, together with the concentration profile obtained by Ching and $\mathrm{Lu}$ (1997). This profile resulted from the simulation using the equivalence model approach for the reactive SMB unit. The equations were made discrete by the method of finite volumes and interpolation functions from the WUDS (Weight Upstream Differencing Scheme) were used. The computational grid was 62 control volumes in the axial direction and 3 control volumes in the radial position, with an integration time step of 1 second. Details can be found in Borges da Silva (2004).

To describe the behavior of the system, Ching and $\mathrm{Lu}$ (1997) also employed the equivalence model of the simulated movement of the solid phase with its actual flow, that is, from the reactive units of simulated moving bed with those of true moving bed. Fig. 4 shows that the profiles present very good agreement, validating the numerical methodology used. The performance of the unit as measured by the purity of the fructose collected in the extract stream was $53.3 \%$. This value was too low if was thought that feed was equimolar sugar mixture. But important point was eluent economy from Hashimoto's system (Hashimoto et al, 1993). As could be seen in Table 4 with regard to the values suggested by Ching and Lu (1997), the flows were considerably higher than those employed by Hashimoto et al. (1983). In Fig. 4, section 3 commenced with an undesirable reaction of fructose being converted to glucose. Under the 
conditions of Ching and Lu this did not occur, as confirmed by the results illustrated in Fig. 5 .

The number of subsections in the previous cases was considerable. The parameters of the model and operating conditions given in Table 5 were proposed for operation of the Simulated Moving Bed reactor of the system in Fig. 3. The operating conditions were estimated considering the theory of equilibrium and the isotherms of adsorption.

Table 4 - Values of the flow parameters for operation of the system investigated.

\begin{tabular}{cccc}
\hline No section & $\mathbf{1}$ & $\mathbf{2}$ & $\mathbf{3}$ \\
\hline$\gamma_{G l}^{*}$ & \multicolumn{2}{c}{ Hashimoto et al. (1983) } \\
$\gamma_{F r}^{*}$ & 1.34 & 1.02 & 1.10 \\
& 1.14 & 0.87 & 0.94 \\
$\gamma_{G l}^{*}$ & \multicolumn{2}{c}{ Ching and Lu (1997) } \\
$\gamma_{F r}^{*}$ & 1.87 & 0.82 & 1.04 \\
\hline
\end{tabular}
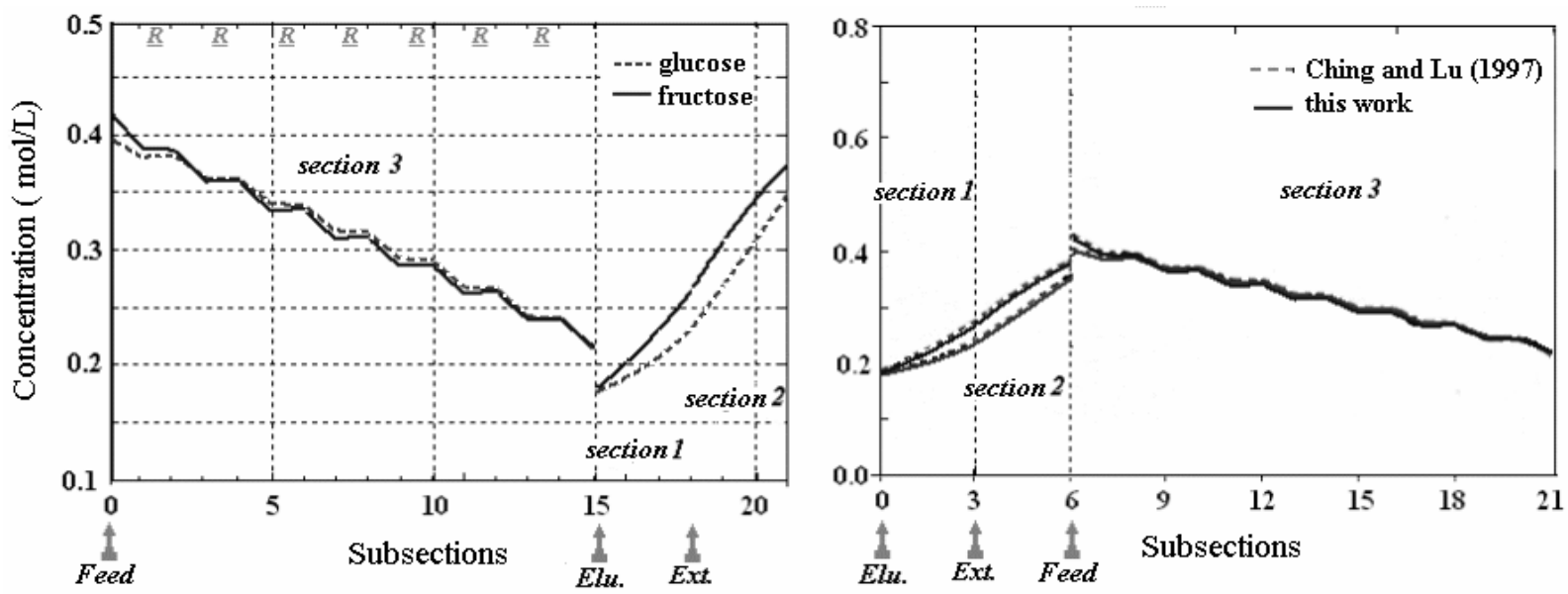

Figure 4 - (a) Average concentration profile of the sugars through the unit in the cyclic steady state.

(b) Comparison: (---) Ching and Lu (1997); ( - ) this study. Purity (Ex): $53.3 \%$.

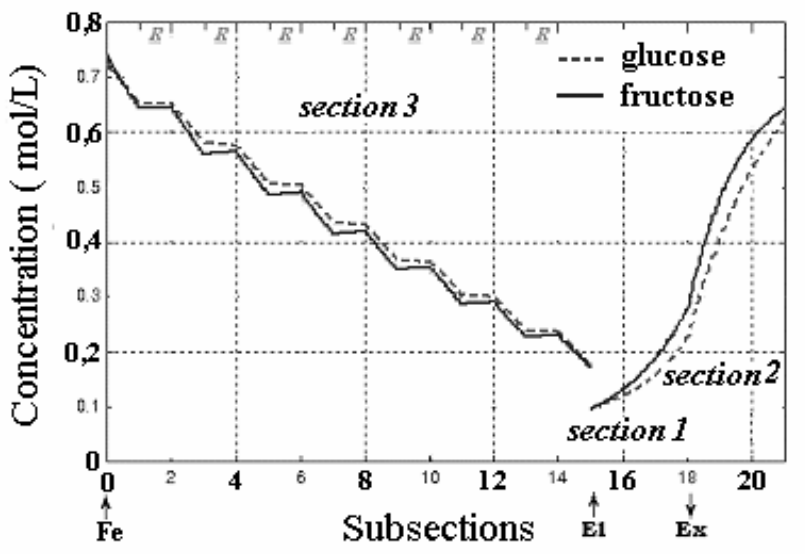

Figure 5 - Concentration profile in a SMBR. Operating conditions: Table 1 (Parameters proposed by Ching and Lu (1997)). Purity (Ex): 55.2\%. 
The model parameters were characteristic when a cationic exchange resin was used as adsorbent phase (Azevedo, 2001). The reaction rate was that obtained experimentally.

By analyzing Fig. 6 it could be seen that in the fixed bed reactors the glucose was converted into fructose, and soon after the species passed to an adsorption column that created the concentration differential for the entry of the mixture of isomers in the next reactor. In the last reactor, a situation of equilibrium was practically reached by the end of the reactor.

Table 5 - Operating conditions and model parameters of glucose isomerization in a SMBR.

\begin{tabular}{cccc}
\hline \multicolumn{2}{c}{ Operating Conditions } & \multicolumn{2}{c}{ Parameters } \\
\hline$C_{G l, o}$ & $1.0 \mathrm{M}$ & $k_{T M}^{F r}$ & $1.33 \mathrm{~min}^{-1}$ \\
$C_{F r, o}$ & $1.0 \mathrm{M}$ & $k_{T M}^{G l}$ & $1.89 \mathrm{~min}^{-1}$ \\
$Q_{F e}$ & $1.50 \mathrm{~mL} / \mathrm{min}$ & $K_{F r}$ & 0.53 \\
$Q_{E l}$ & $5.60 \mathrm{~mL} / \mathrm{min}$ & $K_{G l}$ & 0.27 \\
$Q_{3}$ & $25.5 \mathrm{~mL} / \mathrm{min}$ & Num. Columns & 13 \\
$t^{*}$ & $3.84 \mathrm{~min}$ & & $(5 \underline{\mathrm{A}}-4 \mathrm{R}-2-2)$ \\
$\varepsilon ; \varepsilon_{r}$ & 0.4 & $L_{C}$ & $30 \mathrm{~cm}$ \\
\hline
\end{tabular}

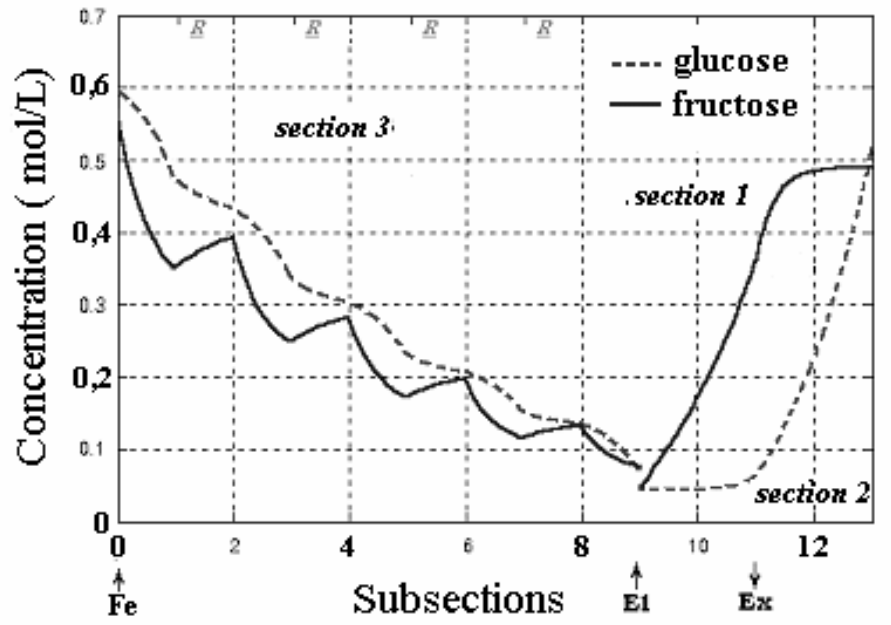

Figure 6 - Concentration profile in a SMBR. Operating conditions: Table 3. Purity (Ex): $85 \%$.

At the end of section 3, the eluent was recycled to section 1, since the concentration of glucose decreased sufficiently for it not to contaminate the fructose product recovered in the extract stream. The purity of the product obtained with the conditions described in Table 5 was $85 \%$. It was possible, therefore, to use the system in Fig. 3 in the process of glucose isomerization to obtain the fructose with increased purity.

The effect of variation in the flow rate of the feed stream on the performance of the reaction/ separation of isomers, in the reactive simulated moving bed unit shown in Fig. 1, was verified through three performance variables: purity, consumption of eluent and productivity. This study was carried out through an analysis of Fig. 7, which presented the effect of a change in the flow rate of the feed stream maintaining the switching time and the flow rate of the eluent stream constant and equal to $7.10 \mathrm{~mL} / \mathrm{min}$ and $3.84 \mathrm{~min}$, respectively. The extract stream flow varied in such a way as to preserve the global mass balance. The other parameters were those given in Table 5. In Fig. 7, it could be seen that with the increase in the flow rate of the feed stream, there was a decrease in the purity of the fructose in the extract 
stream. With the increase in the feed flow rate, the velocity in section 2 decreased, influencing the liquid flow of the species in the opposite direction to the fluid phase. This could lead to contamination of the glucose in the extract stream, decreasing, therefore, the purity of the fructose in this stream, due to the glucose not being completely desorbed.

With regard to the consumption of eluent and the productivity, it could be seen that both were favorable when an increase in the flow rate of feed stream occurred. The concentration of the product was higher in elevated flow rates of feed stream.
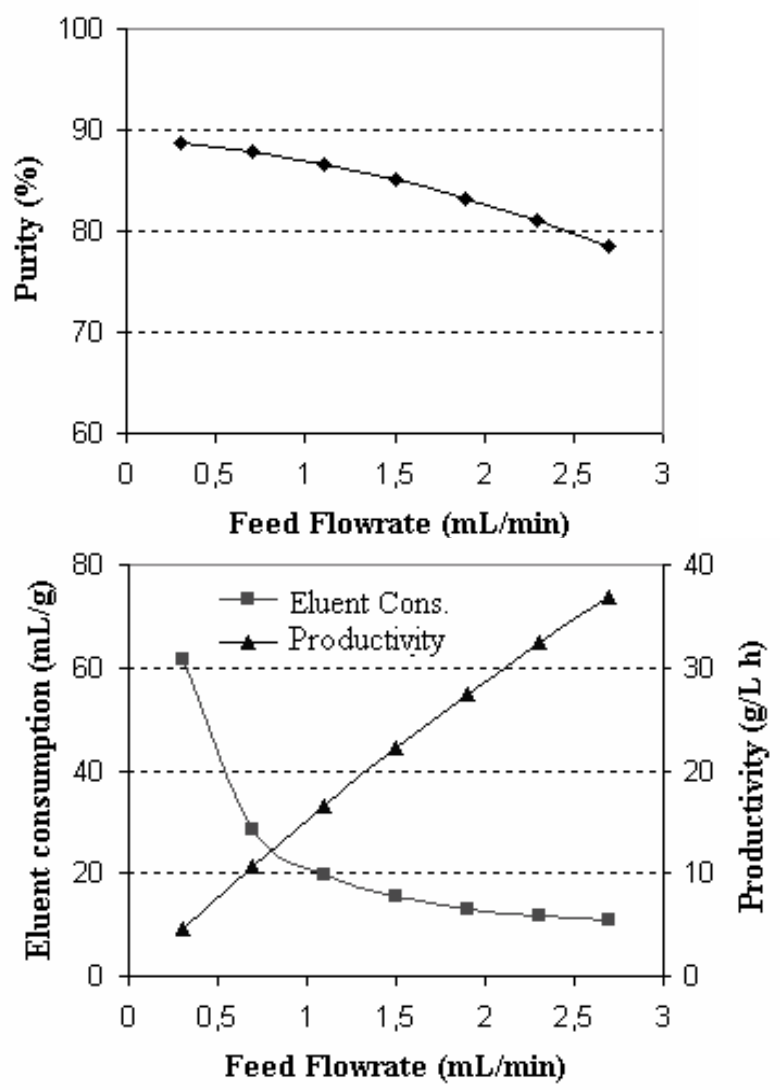

Figure 7 - Influence of the flow rate of feed stream (fixing the flow rate of the eluent stream) on the performance of the SMBR in the glucose isomerization.

\section{CONCLUSION}

The SMBR technology was employed in the process of glucose isomerization. A SMBR configuration composed of fixed bed reactors and adsorption columns in the same unit was evaluated. The behavior and the performance of this unit could be predicted numerically by an equivalence model, with the numerical results obtained having a good level of agreement with data found in the literature. Employing the numerical methodology it was possible to show that the system presented provided the isomerization product - fructose - with greater purity and with a saving on eluent, since this was entirely recycled.

The reaction kinetics of the glucose isomerization were obtained experimentally for the immobilized enzyme glucose isomerase (Sweetzyme IT) using jacketed batch reactors. Diffusional effects through the stagnant layer and within particles were observed to be negligible. The influence of variation in the flow rate of feed stream on the performance of the system was assessed. For low flows, a greater purity of product could be obtained, in detriment to the productivity and the consumption of eluent. Through this study, the best operating conditions for a given application of the unit was established. 


\section{ACKNOWLEDGMENTS}

Financial support from National Council for Scientific and Technological Development $(\mathrm{CNPq})$ and Coordination for the Improvement of Higher Education Personnel Foundation (CAPES) is gratefully acknowledged. We acknowledge to the staff of the LSRE, where the experimental work was done.

\section{RESUMO}

Neste trabalho a tecnologia de Leito Móvel Simulado (LMS) reativo é aplicada no processo de isomerização da glicose visando à produção de xarope concentrado de frutose. É apresentada a modelagem matemática e uma metodologia numérica para predizer o comportamento e o desempenho de unidades reativas de leito móvel simulado para verificar alguns aspectos importantes para o emprego desta tecnologia no processo de isomerização. $\mathrm{O}$ algoritmo desenvolvido utiliza a abordagem que considera as equivalências entre as unidades reativas de leito móvel simulado e leito móvel verdadeiro. Parâmetros cinéticos da reação enzimática são obtidos experimentalmente usando reatores em batelada pela técnica Lineweaver-Burk. Efeitos da transferência de massa na conversão de reação usando a enzima imobilizada glicose isomerase são verificados. No sistema reativo de LMS, a variável operacional vazão da corrente de alimentação é avaliada para conhecer o efeito de sua influência no desempenho do sistema. Verificou-se que existem valores de vazões onde maiores purezas podem ser obtidas.

\section{REFERENCES}

Azevedo, D. C. S. (2001), Separation and reaction in simulated moving bed - Application to the production of industrial sugars. PhD Thesis, University of Porto, Porto, Portugal.

Borges da Silva, E. A. (2004), Estudo da transferência de massa em unidades de leito móvel simulado reativo. PhD Thesis, Universidade Federal de Santa Catarina, Florianópolis, SC, Brazil.

Chen, K. and Wu, J. (1987), Substrate protection of immobilized glucose isomerase. Biotechnology and Bioengineering, 30, 817-824.
Ching, C. B.; Ho, C.; Hidajat, K. and Ruthven, D. M. (1987), Experimental study of a simulated countercurrent adsorption system - V: Comparison of resin and zeolite absorbents for fructose-glucose separation at high concentration. Chem. Eng. Sci., 42 : (11), 2547-2555.

Ching, C. B. and Lu, Z. P. (1997), Simulated movingbed reactor: application in bio-reaction and separation. Ind. Eng. Chem. Res., 36, 152-159.

Converti, A. and Del Borghi, M. (1997), Simultaneous effects of immobilization and substrate protection on the thermodynamics of glucose isomerase activity and inactivation. Enzyme and Microbial Technology, 21, 511-517.

Hashimoto, K.; Adachi, S.; Noujima, H. and Ueda, Y. (1983), A new process combining adsorption and enzyme reaction for producing higher-fructose syrup. Biotechnology and Bioengineering, 15, 2371-1393.

Hashimoto, K.; Adachi, S. and Shirai, Y. (1993), Development of new bioreactors of a simulated moving-bed type. In: Ganetsos, G. and Barker, P. E. (Eds.). Preparative and production scale chromatography. New York: Marcel Dekker Inc.

Linko, M.; Poutanem, K. and Linko, Y. Y. (1981), Reactor performance in glucose isomerization by cellulose bead immobilized actinoplanes cells. Journal Molecular Catalysis, 13, 263-271.

Palazzi, E. and Converti, A. (2001), Evaluation of diffusional resistances in the process of glucose isomerization to fructose by immobilized glucose isomerase. Enzyme and Microbial Technology, 28, 246-252.

Silva, E. A. B.; Ulson de Souza, A. A.; Guelli, U. and Souza, S. M. A. (2002), The use of simulated moving bed in chromatographic separation: study of the SMB configuration. Separation Science and Technology, 37, 1489-1504. 